\title{
Interim Analysis Program
}

National Cancer Institute

\section{Source}

National Cancer Institute. Interim Analysis Program. NCI Thesaurus. Code C115484.

A computer application designed to generate an interim analysis output as referenced by a statistical analysis plan (SAP). 